\title{
CFD modelling of small scale ORC scroll expanders using variable wall thicknesses
}

\author{
Simon Emhardt ${ }^{\mathrm{a}}$, Guohong Tian ${ }^{\mathrm{a}, *}$, Panpan Song ${ }^{\mathrm{b}}$, John Chew $^{\mathrm{a}}$, Mingshan Wei $^{\mathrm{b}}$ \\ aDepartment of Mechanical Engineering Sciences, University of Surrey, Guildford, Surrey, GU2 7XH, UK \\ ${ }^{\mathrm{b} S}$ School of Mechanical Engineering, Beijing Institute of Technology, Beijing 100081, China
}

\section{Corresponding author:}

Dr. Guohong Tian

Address: Department of Mechanical Engineering Sciences, University of Surrey

388 Stag Hill, Guildford, Surrey, GU2 7XH, UK

Tel: +44(0)1483689283

E-mail: g.tian@surrey.ac.uk

\section{HIGHLIGHTS}

\author{
- An unsteady 3D CFD model for a variable wall thickness scroll expander was developed \\ - The highest isentropic efficiency of $53.9 \%$ was reached at a pressure ratio of 3.5 \\ - The vortices in the expansion chambers were fully dissipated at a crank angle of $600^{\circ}$ \\ - Scroll expanders with built-in volume ratios above 4.5 could achieve a full expansion
}

Keywords: Unsteady 3D CFD concept, Variable wall thickness, Scroll expander, ORC system, Pressure trace analysis, Energy dissipation

\begin{abstract}
The built-in volume ratio of variable wall thickness scroll expanders can be increased without increasing the number of scroll turns and the expander size in contrast to constant wall thickness expanders. CFD models for these novel scroll-type designs are presented in this research paper. The validation, verification and the findings had proven consistency with the theory of small scale ORC scroll expanders. The performance analysis indicates that the optimum performance point was reached at a pressure ratio of 3.5. The decrease of radial clearance from $200 \mu \mathrm{m}$ to $75 \mu \mathrm{m}$ had a significant effect on the isentropic efficiency and the specific power output, with the isentropic efficiency significantly increasing from $31.9 \%$ up to $53.9 \%$. Based on the second-law analysis, it is found that exergy of $336.5 \mathrm{~W}(75 \mu \mathrm{m})$ and $864.2 \mathrm{~W}(200 \mu \mathrm{m})$ were destroyed during the expansion
\end{abstract}


processes. Furthermore, characteristic pressure imbalances were observed in the expansion chambers. The studies also reveal that the large-scale vortices, generated during the suction process, were completely dissipated in the expansion chambers at a crank angle of $600^{\circ}$. Analysis of the pressure-volume diagram shows that variable wall thickness scroll expanders with builtin volume ratios above 4.5 could fully expand the working fluid to the defined outlet pressure.

\section{Introduction}

There is a wide variety of different expansion machines, such as axial and radial-inflow turbines, screw expanders, reciprocating expanders, rotary vane expanders, axial piston expanders, roots expanders and scroll expanders, which are suitable for use in small-scale organic Rankine cycle (ORC) systems [1-5]. Dumont et al. (2018) [5] were one of the first few who aimed to simplify the choice of the optimum expander for small-scale ORC units. They compared the performances of four different expanders. The experimentally obtained data was used for the calibration of a semi-empirical model to create ideal performance maps for those volumetric expansion machines using R245fa. Their studies indicated that the highest isentropic efficiency of $76 \%$ was achieved for the scroll expander followed by the piston and screw (53\%) and the roots expander (47\%). Olmedo et al. (2018) [6] also used experimental results, determined from a literature review, to calibrate their semiempirical model. It was subsequently applied to design non-dimensional performance maps for scroll expanders lubricated with oil and integrated into micro-scale ORC systems. Non-dimensional factors such as specific speed $\left(\mathrm{N}_{s}\right)$ and specific diameter $\left(\mathrm{D}_{s}\right)$ were derived from the turbomachinery field and incorporated into these maps to simplify the scroll geometry optimisation in terms of built-in volume ratio and scroll height. It was possible to predict isentropic efficiencies up to $80 \%$ based on the measured electrical power output.

In addition to scroll expanders being found to be a promising solution for ORC systems, scientific investigations have identified a strong dependence of the scroll expander performance on the value of the built-in volume ratio [7-13]. As a consequence, Clemente et al. (2012) [11] conducted numerical analysis of two scroll machines with different scroll profile lengths. There was a shift of the operational field towards higher pressure ratio (PR) which in turn led to higher power output for the scroll expander with the long scroll. However, the 
isentropic efficiency was higher for the short scroll. Similar observations were made in the investigations of Chang et al. $(2014,2015)[12,13]$ who experimentally examined three scroll expanders distinguished by increasing builtin volume ratios of $2.12,2.95$ and 4.05 . It can be noted that the highest isentropic efficiency of $76 \%$ was achieved for the built-in volume ratio of 2.95 compared to $73.1 \%$ for the built-in volume ratio of 4.05 . The higher number of scroll turns resulted in increased losses due to friction and internal leakages. A comprehensive review of scroll expander geometries and their impact on the performance was also provided by the authors [14].

The published academic research on scroll machines using variable wall thicknesses has demonstrated a number of benefits associated with this approach. In particular, for a given scroll profile length, the scroll machine with variable wall thickness features a higher built-in volume ratio with respect to a constant wall thickness design [15-22]. The reason for this lies in the variation of the wall thickness along the expansion and discharge chambers. Liu et al. $(2010,2012)[20,21]$ developed a geometrical model to generate a scroll compressor with variable wall thickness which was subsequently employed to carry out a finite element analysis. The radial and axial deformations were lower than those predicted for a constant wall thickness scroll compressor characterised by the same built-in volume ratio, suction volume and the endplate diameter of the moving scroll. However, variable wall thickness scroll expanders are not widely investigated and the effect on the expansion process is almost unknown since the research and development of these innovative expander designs is still in the early stages. No experimental research is available and all the literature can be narrowed down to theoretical studies [14].

CFD simulations of scroll machines have been increasingly conducted in recent years for investigation of the inner working process [12,23-28]. The understanding developed has contributed to performance predictions which are useful for preliminary design and the further improvement of the scroll geometry itself. A few researchers examined their scroll machines with the help of a 2D CFD approach $[23,24]$. In comparison to a 3D CFD model, the 2D CFD model of Chang et al. (2014) [12] revealed a similar prediction of the pressure and volume change during the expander working process with a small deviation during the expansion process. Song et al. (2015) [25] identified that the main challenges were the development of three-dimensional, unsteady and two-phase flow CFD 
models. This would enable the capture of spatial inner flow characteristics, evaluation of accurate time-averaged flow and temperature fields and consideration of the effects of lubricating oil. Drawing upon these findings, Song et al. $(2015,2018)$ [26-28] established a 3D CFD model to analyse the inner working process of a scroll expander with a particular focus on the unsteady suction process and the effects of suction port arrangements. They also developed a CFD model for a small-scale ORC scroll expander with a bilateral discharge structure (two discharge ports) to investigate its influence on the expander aerodynamic performance.

Previous CFD simulations were based on scroll machines with constant wall thicknesses. Rak et al. (2014) $[29,30]$ for the first time developed a 2D CFD model for the variable wall thickness geometry proposed by Bush and Beagle $[15,16]$. The results showed that the wall heat transfer coefficient for the variable wall thickness chamber was up to three times larger than that in the constant wall thickness chamber. This contrasted with the impact of the rotational speed on the coefficient which was greater for the constant wall thickness design. However, the 2D CFD approach in combination with the assumption of no clearances (and hence no leakage) restricted the accuracy. Emhardt et al. (2019) [31] carried out CFD simulations for variable wall thickness scroll expanders. Over- and under-expansion phenomena occurred at two pressure ratios of 2.5 and 5.5 which was in accordance with the thermodynamic theory of scroll expanders. Nevertheless, a detailed evaluation of the variable wall thickness scroll expander performance under a wide range of operating conditions was not included. No detailed descriptions of the three-dimensional and time-dependent expansion process of these novel variable wall thickness expander designs has been found in the open literature.

In this paper, CFD simulations of small scale ORC scroll expanders using variable wall thicknesses are presented based on a three-dimensional and transient approach. The main purpose of the current paper is to prove the thermodynamic theory in addition to the demonstration of the CFD capability for these innovative and novel variable wall thickness scroll expander designs. The refrigerant R123 was used as the working fluid. The clearances were not sealed by means of lubricant oil, so a dry wall expander design was considered. The first part of the paper focuses on the verification and validation of the CFD model including grid and turbulence model 
sensitivity tests. The CFD results are analysed in the second part of the paper. Scroll expander isentropic efficiency and power output for increasing pressure ratio are examined and second-law efficiency is evaluated. In addition to the influence of variable wall thicknesses on the scroll expander aerodynamic performance, the pressure distribution and the pressure-Volume $(\mathrm{p}-\mathrm{V})$ diagram along with the unsteady three-dimensional flow field are investigated.

\section{Description of the scroll profiles}

The scroll expander geometry using variable wall thicknesses was created by means of the equations which Bin et al. (2016) $[18,19]$ used in their development of a geometrical and thermodynamic model for a scroll compressor. The scroll profile is driven by a high order curve on the basis of the involute of a circle approach as visualised in Fig. 1. The fixed scroll is coloured in red whereas the orbiting scroll is coloured in blue. It can be also seen that two arcs are used to fabricate the dual arc tip design. The geometrical model parameters of the variable wall thickness design are contained in Table 1.

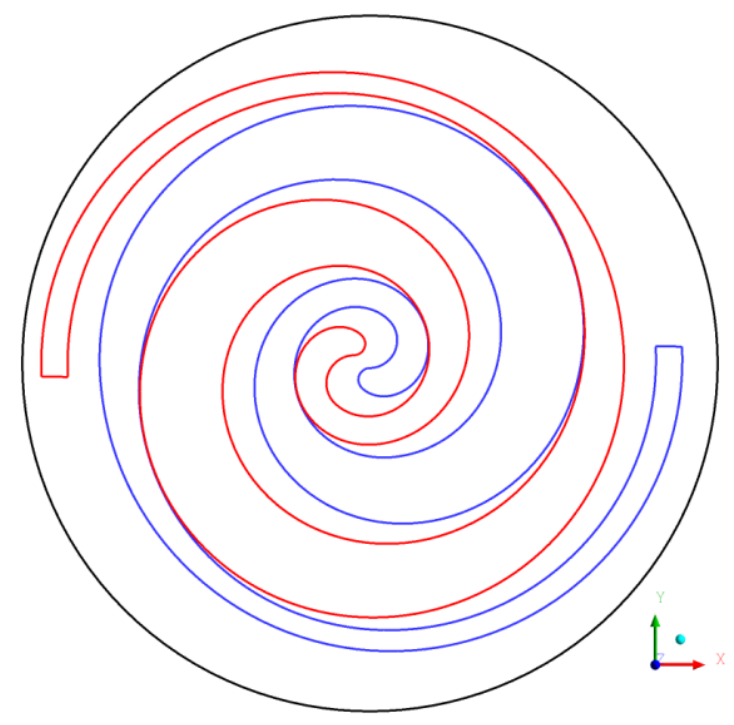

Fig. 1: Geometrical model of the scroll expander using variable wall thicknesses
Table 1: Geometrical model parameters for the creation of the variable wall thickness expander design $[18,19]$

\begin{tabular}{llll}
\hline Parameter & Definition & Unit & Value \\
\hline$\alpha$ & Original angle & $(-)$ & 0.993 \\
$\mathrm{a}$ & Base circle radius & $(\mathrm{mm})$ & 2.25 \\
$\mathrm{~h}$ & Scroll height & $(\mathrm{mm})$ & 20 \\
$\mathrm{r}_{\mathrm{ob}}$ & Orbiting radius & $(\mathrm{mm})$ & 2.6 \\
$\mathrm{R}$ & Big circular arc radius & $(\mathrm{mm})$ & 4.4279 \\
$\mathrm{r}$ & Small circular arc radius & $(\mathrm{mm})$ & 1.8279 \\
\hline $\mathrm{C}_{0}$ & Constant of wall thickness & $(-)$ & 32.1464 \\
$\mathrm{C}_{1}$ & Constant of wall thickness & $(-)$ & -11.821 \\
$\mathrm{C}_{2}$ & Constant of wall thickness & $(-)$ & 2.1066 \\
$\mathrm{C}_{3}$ & Constant of wall thickness & $(-)$ & -0.0868 \\
$\mathrm{k}$ & Control parameter of wall & $(-)$ & -46.075 \\
& thickness & & \\
$\mathrm{d}$ & Control parameter of wall & $(-)$ & 3.375 \\
& thickness & & \\
\hline $\mathrm{r}_{v}$ & Built-in volume ratio & $(-)$ & 4.5 \\
\hline & & & \\
\hline & & & \\
& & &
\end{tabular}




\section{Numerical procedure}

The numerical procedure comprising the principles and theoretical equations, applied to develop a CFD model for the variable wall thickness scroll expander design, is outlined in this section. The generation of a 3D unstructured grid, to discretise the computational domain along with the dynamic mesh technology to update the deforming mesh over time, is described in the first sub-section. The initial and boundary conditions used, as well as the solution methods such as the spatial and temporal discretisation schemes for the computational procedure, are considered in the second sub-section.

\subsection{Grid generation}

As previously mentioned, a few researchers have created models based on a 3D CFD approach. Following other workers practice, a three-dimensional computational grid was created to capture the inner flow field within the scrolls. An inlet pipe, pre-chamber, suction pipe, and outlet pipe were combined with the scroll expander chamber which incorporates the entire scroll expander geometry as shown in Fig. 2.

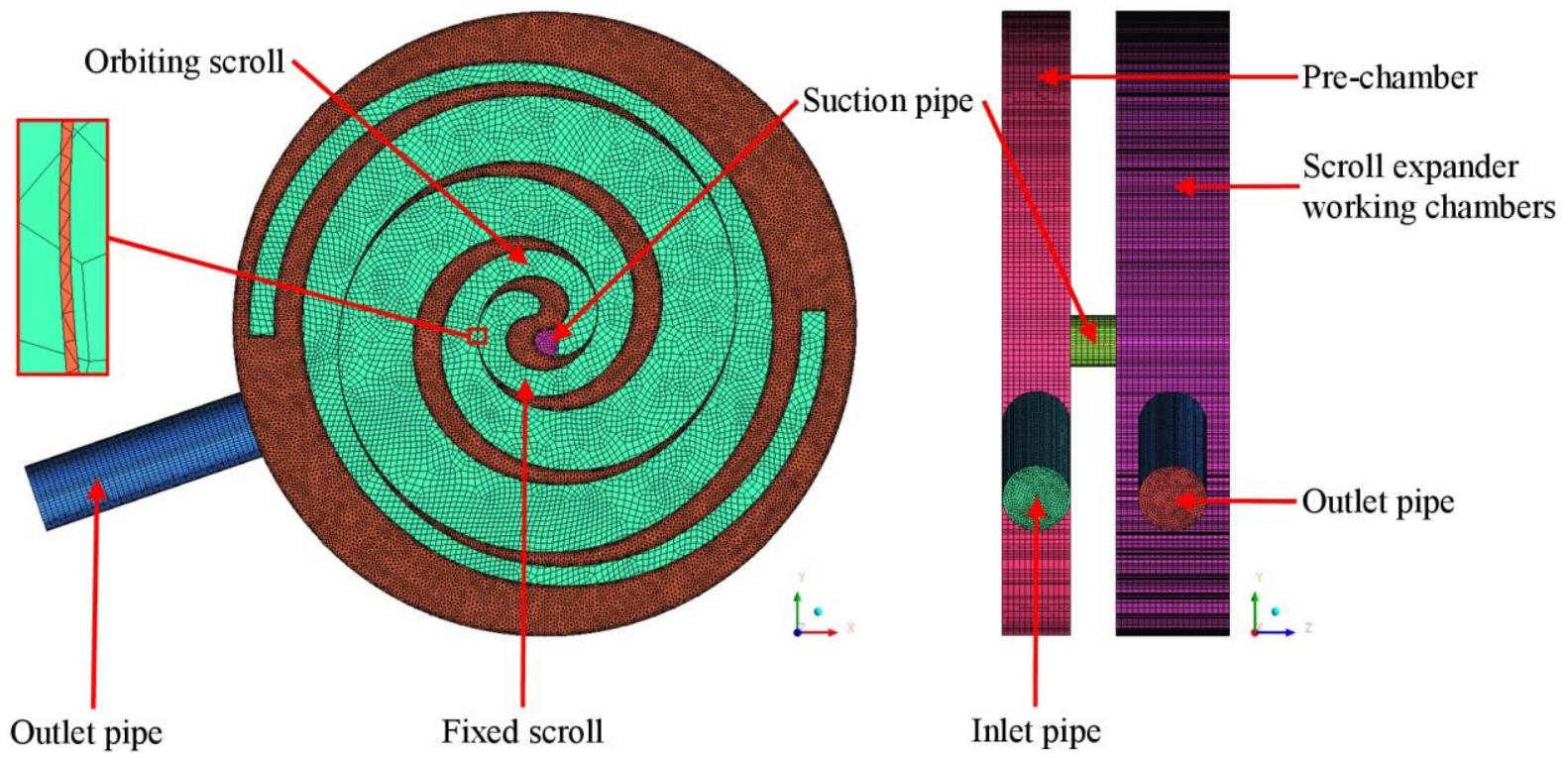

Fig. 2: 3D unstructured grid for a scroll expander made of variable wall thicknesses - end view (left) and side view (right) 
The grid generator ICEM was used to create the unstructured grid based on the grid of Wei et al. (2015) [26]. Their work contained an experimental validation. The unstructured mesh approach has also been used by other researchers $[12,24,33]$. The mesh report in Table 2 shows the number of nodes and cells for each domain of the computational grid for two variable wall thickness scroll expanders with radial clearances of $200 \mu \mathrm{m}$ and $75 \mu \mathrm{m}$ respectively. The values of the radial clearances have been chosen for computational reasons and for consistency with earlier studies ([26]). Lower radial clearances would have resulted in a much finer resolution of those gaps which in turn would have increased the total number of nodes and cells massively. Hence, the radial clearance was set to $200 \mu \mathrm{m}$ and $75 \mu \mathrm{m}$ in the present work to balance between computational time and accuracy of the numerical results. The focus lies on a three-dimensional and transient analysis of the flow field in the scroll expander working chambers rather than on the leakage flows through the radial clearance. The single-layer grid along the narrow gaps between fixed and orbiting scroll was therefore assumed to be applicable. The axial clearances were excluded.

Table 2: Mesh report

\begin{tabular}{lrr}
\hline Domain & Number of nodes & Number of cells \\
\hline Suction pipe & 2871 & 2280 \\
Inlet pipe & 28905 & 26240 \\
Outlet pipe & 29971 & 27240 \\
Pre-chamber & 139009 & 125556 \\
Scroll expander chambers $(200 \mu \mathrm{m})$ & 295113 & 503660 \\
Scroll expander chambers $(75 \mu \mathrm{m})$ & 439971 & 709680 \\
\hline All domains $(200 \mu \mathrm{m})$ & 495869 & 684976 \\
All domains $(75 \mu \mathrm{m})$ & 640727 & 890996 \\
\hline
\end{tabular}

The dynamic mesh technology provided by ANSYS FLUENT [32] was employed to generate the eccentric movement of the orbiting scroll relative to the fixed scroll while changing the enclosed working chamber volumes over time. The dynamic mesh is the most common approach to capture the fluid motion in the complex scroll expander geometry and to reproduce the eccentric movement of the orbiting scroll by means of user-defined functions $[12,24,26-28,33,34]$. The smoothing and remeshing dynamic mesh schemes were combined and enabled in order to regenerate and recalculate the deforming and moving mesh in the expander working chambers at each 
time step. The equations solved using the dynamic mesh technique incorporate all the governing equations for continuity, momentum and energy conservation in the calculation of the dynamic motion. The orbiting scroll rotates at a constant speed about the gravity centre.

\subsection{Turbulence modelling and boundary conditions}

The computational fluid dynamics software ANSYS FLUENT 18.0 was applied to perform the CFD simulations based on the unsteady Reynolds-averaged Navier-Stokes (URANS) approach. The standard k- $\epsilon$ turbulence model and the re-normalisation group (RNG) $k-\epsilon$ turbulence model were used to investigate the influence of different turbulence models on the solution. While the standard $k-\epsilon$ model is widely accepted, some sources recommend the RNG model for complex flows, such as strained and swirling flows as in the present case [32]. The energy equation was applied in combination with the continuity and Navier-Stokes equations to investigate the temperature fields in the scroll expander working chambers. The PISO-Algorithm was employed to solve the Navier-Stokes equations by determining the pressure from the coupled system of continuity and momentum equations with the help of a pressure correction technique. The Green-Gauss node-based method was applied for the computation of the gradients of any given scalar at the centre of each cell. This method is claimed to achieve good accuracies in computational domains discretised by unstructured meshes [32]. The PRESTO scheme was applied for the interpolation of the pressure values because the computational domain includes extreme curvatures, rotating flows, large pressure and velocity fluctuations and high velocity gradients. For such flows, it has been reported [32] that PRESTO gives better accuracy than standard pressure interpolation schemes, but at the expense of longer computational times. Second-order upwind schemes were applied for the spatial discretisation of the density, momentum and energy equations respectively. The first-order upwind schemes were enabled for the turbulence equations. The first-order implicit unsteady formulation was utilised to run the transient CFD simulations with the pressure-based solver. This formulation is recommended in consideration of the simulation accuracy, stability and process time [32]. 
The time step of $\Delta \mathrm{t}=5 \times 10^{-5} \mathrm{~s}$ was specified to achieve convergence and obtain accurate solutions. This corresponds to one-six-hundredth of a scroll revolution for the rotational speed of 2000rpm. Eq. (1) defines the ratio of work per cycle calculated from angular momentum change $\left(\dot{W}_{a}\right)$ to that calculated from total enthalpy change $\left(\dot{W}_{h}\right)$. This can be used to judge convergence, as it should be equal to unity when the overall energy balance is satisfied by the solution.

$$
\frac{\dot{W}_{a}}{\dot{W}_{h}}=\frac{\int_{t_{1}}^{t_{2}}(\tau \cdot n) d t}{\int_{t_{1}}^{t_{2}} \dot{m}\left(h_{t, \text { out }}-h_{t, \text { in }}\right) d t}=1
$$

$\tau$ and $n$ define the scroll expander torque and rotational speed respectively. $\dot{m}$ is specified as the mass flow rate through the system and $h_{t, \text { out }}$ and $h_{t, \text { in }}$ are denoted as the specific total enthalpies at the scroll expander inlet and outlet. $t_{1}$ and $t_{2}$ fix the initial and final state of one revolution of the orbiting scroll. Moreover, residual levels and quantities of the internal flow field in specific points were monitored to reach convergence.

No-slip boundary conditions were applied to the corresponding walls of the domain. The first cell was resolved in the fully turbulent flow region with the help of standard wall functions. The total inlet pressure and total inlet temperature in combination with the static outlet pressure and backflow total temperature were applied as boundary conditions for the inlet pipe inlet and outlet pipe outlet respectively. The NIST (National Institute of Standards and Technology) real gas model for the refrigerant R123 from the REFPROP (Reference Fluid Thermodynamic and Transport Properties) database was selected to model the thermodynamic and transport properties of the working fluid [32,35]. The energy source due to viscous dissipation was included in the energy equation as appropriate for a high-velocity compressible flow.

\section{CFD model verification and validation}

To the best of the authors knowledge, no experimental research studies are available in the literature on variable wall thickness scroll expanders. Moreover, three-dimensional and transient CFD studies are limited to conventional scroll geometries. Hence, the predicted CFD results are compared with the numerical and 
experimental findings obtained from the constant wall thickness scroll expander of Wei et al. (2015) [26]. The corresponding operating conditions for the CFD model verification and validation are specified by pressure ratio, total inlet temperature and rotational speed. The applied pressure ratios ranged from 2.50 to 2.74 and the total inlet temperatures ranged from $405 \mathrm{~K}$ to $454 \mathrm{~K}$. The rotational speed was varied from $1820 \mathrm{rpm}$ to $2520 \mathrm{rpm}$.

\subsection{Grid sensitivity analysis}

The operating conditions for the CFD model used in grid sensitivity analysis, turbulence model and tangential force distribution tests are listed in Table 3.

Table 3: Operating conditions for the CFD model verification

\begin{tabular}{llllll}
\hline $\begin{array}{l}\text { Total inlet } \\
\text { temperature (K) }\end{array}$ & $\begin{array}{l}\text { Total inlet } \\
\text { pressure (MPa) }\end{array}$ & $\begin{array}{l}\text { Static outlet } \\
\text { pressure (MPa) }\end{array}$ & $\begin{array}{l}\text { Pressure } \\
\text { ratio (-) }\end{array}$ & $\begin{array}{l}\text { Rotational } \\
\text { speed (rpm) }\end{array}$ & $\begin{array}{l}\text { Working } \\
\text { fluid }\end{array}$ \\
\hline 405 & 1.100 & 0.440 & 2.50 & 2000 & R123 \\
\hline
\end{tabular}

Grid sensitivity analysis was conducted to examine the accuracy of the CFD solutions and the results are illustrated in Table 4. It can be observed that the refinement of the grid resulted in less than $2 \%$ change in torque and power. The mass flow rate and isentropic efficiency were constant to within $1.4 \%$ and $0.8 \%$, respectively. This level of grid convergence was considered acceptable for the present study. Considering, in particular, the CPU-time, the grid with $685 \mathrm{k}$ cells was chosen to carry out further CFD simulations.

Table 4: Grid sensitivity analysis

\begin{tabular}{llllll}
\hline $\begin{array}{l}\text { Number } \\
\text { of nodes }\end{array}$ & $\begin{array}{l}\text { Number } \\
\text { of cells }\end{array}$ & $\begin{array}{l}\text { Mass flow } \\
\text { rate }(\mathbf{k g} / \mathbf{s})\end{array}$ & $\begin{array}{l}\text { Torque } \\
\mathbf{( N m )}\end{array}$ & $\begin{array}{l}\text { Power } \\
\text { output }(\mathbf{W})\end{array}$ & $\begin{array}{l}\text { Isentropic } \\
\text { efficiency (\%) }\end{array}$ \\
\hline $372 \mathrm{k}$ & $458 \mathrm{k}$ & 0.0485 & 1.280 & 268.11 & 33.30 \\
$496 \mathrm{k}$ & $685 \mathrm{k}$ & 0.0478 & 1.269 & 265.84 & 33.36 \\
$794 \mathrm{k}$ & $1227 \mathrm{k}$ & 0.0482 & 1.295 & 271.16 & 34.07 \\
\hline
\end{tabular}

\subsection{Sensitivity study on turbulence modelling}

Table 5 shows the effects of different turbulence models on the expander performance. The RNG k- $€$ model predicted a slightly higher average mass flow rate, torque and power output in comparison to the standard k- $\epsilon$ 
model. These differences are related to the RNG approach which is said to model the impact of swirling flows on turbulence more accurately [32]. The variations in isentropic efficiency were negligible as they were within $0.2 \%$. In other words, the turbulence sensitivity tests show that the CFD model was robust against different turbulence models. Hence, the RNG k-€ model was chosen for further investigations for consistency with earlier studies [26].

Table 5: Influence of different turbulence models on the performance

\begin{tabular}{lllll}
\hline $\begin{array}{l}\text { Turbulence } \\
\text { model }\end{array}$ & $\begin{array}{l}\text { Mass flow } \\
\text { rate }(\mathbf{k g} / \mathbf{s})\end{array}$ & $\begin{array}{l}\text { Torque } \\
\mathbf{( N m )}\end{array}$ & $\begin{array}{l}\text { Power } \\
\text { output }(\mathbf{W})\end{array}$ & $\begin{array}{l}\text { Isentropic } \\
\text { efficiency (\%) }\end{array}$ \\
\hline $\mathrm{k}-\epsilon$ & 0.0476 & 1.266 & 265.10 & $33.57 \%$ \\
RNG k- $\epsilon$ & 0.0478 & 1.269 & 265.84 & $33.36 \%$ \\
\hline
\end{tabular}

\subsection{Tangential force distribution and average torque per average mass flow rate for different pressure ratios}

The total tangential force $\left(F_{t}\right)$ exerted on the orbiting scroll of the variable wall thickness scroll expander can be determined using Eq. (2).

$$
F_{t}=\sum_{i=1}^{n}\left(F_{y, i} \cos (\omega t)-F_{x, i} \sin (\omega t)\right)
$$

$F_{x, i}$ and $F_{y, i}$ define the $\mathrm{x}$ - and y-components of the corresponding gas forces and $\omega$ denotes the angular velocity.

The variable $i$ is specified as the orbiting scroll surface element and the variable $n$ represents the total number of the orbiting scroll surface elements. The CFD results (blue curve) are plotted over four revolutions of the orbiting scroll as illustrated in Fig. 3. The plot also includes a comparison against Wei et al.'s CFD results for their constant wall thickness scroll expander (2015) [26] (red curve) at the same pressure ratio of 2.5 as listed in Table 3. 


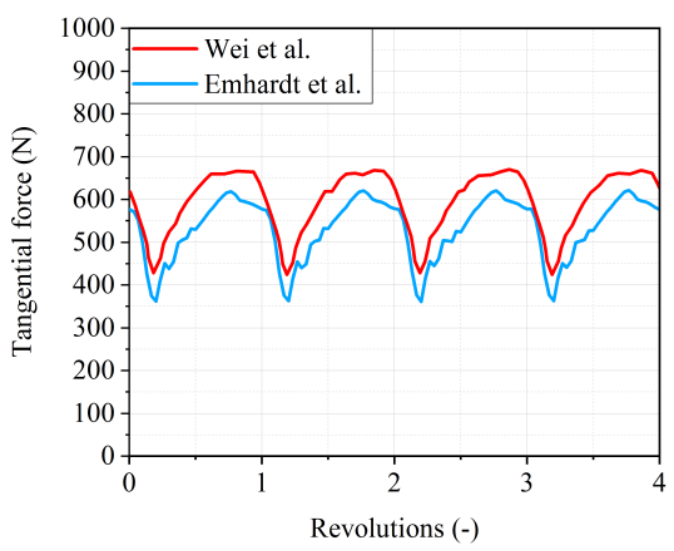

Fig. 3: Tangential force distribution over four revolutions of the orbiting scroll

It can be determined from Fig. 3 that the lowest tangential force acting on the orbiting scroll was generated as soon as the suction port was fully closed in both cases. The highest tangential force was generated as soon as the maximum suction chamber volume was reached. The figure also shows that the tangential force for the variable wall thickness scroll expander design steadily decreased after it reached its peak. It then dropped sharply with the closure of the suction port. This contrasts with the tangential forces for the constant wall thickness design which plateaued before a sharp drop with the closure of the suction port. In addition, the tangential force distribution was smoother and included fewer fluctuations for the constant wall thickness expander. All the aforementioned differences can be associated with the operating mode of the two scroll expander geometries, their different shapes, and their different scroll tip designs. The constant wall thickness design was operated close to its optimum performance point. In comparison to the variable wall thickness design in which an imbalance between pressure and built-in volume ratio existed during the operation ( 2.5 vs. 4.5$)$. The constant wall thickness design uses a perfect meshing profile to generate its scroll tips whereas the variable wall thickness design uses a dual arc tip design to close the scroll tips in the suction area. The comparison shows that the two designs have similar tangential force distributions and demonstrate consistency of present and previous modelling approaches.

There is no experimental data available for the scroll expander using variable wall thicknesses. The predicted CFD results are therefore compared with the numerical and experimental findings obtained from the constant wall thickness scroll expander of Wei et al. (2015) [26]. In spite of the geometrical differences regarding their scroll 
shapes due to varying wall thicknesses, the shape of their working chambers defining the suction, expansion and discharge chambers are similar. This, in turn, makes the two scroll geometries using constant and variable wall thicknesses comparable. The validation of the CFD model was carried out on the basis of four different operating conditions which were used in the previous work and are listed in Table 6.

Table 6: Boundary conditions for the validation of the CFD simulations

\begin{tabular}{llllll}
\hline $\begin{array}{l}\text { Total inlet } \\
\text { temperature (K) }\end{array}$ & $\begin{array}{l}\text { Total inlet } \\
\text { pressure (MPa) }\end{array}$ & $\begin{array}{l}\text { Static outlet } \\
\text { pressure (MPa) }\end{array}$ & $\begin{array}{l}\text { Pressure } \\
\text { ratio (-) }\end{array}$ & $\begin{array}{l}\text { Rotational } \\
\text { speed (rpm) }\end{array}$ & $\begin{array}{l}\text { Working } \\
\text { fluid }\end{array}$ \\
\hline 428 & 1.066 & 0.389 & 2.74 & 1820 & $\mathrm{R} 123$ \\
405 & 1.129 & 0.426 & 2.65 & 2000 & $\mathrm{R} 123$ \\
443 & 0.961 & 0.365 & 2.63 & 2180 & $\mathrm{R} 123$ \\
454 & 0.878 & 0.345 & 2.55 & 2520 & $\mathrm{R} 123$ \\
\hline
\end{tabular}

The scroll expander torque generated by the gas forces can be determined using Eq. (3).

$$
\vec{\tau}=\overrightarrow{r_{0}} \times\left(\overrightarrow{F_{n}}+\overrightarrow{F_{r}}\right)
$$

$\overrightarrow{r_{0}}$ denotes the distance vector between the rotation axis and the force transmission point. $\overrightarrow{F_{n}}$ and $\overrightarrow{F_{r}}$ are defined as the force vectors acting in the normal and radial direction in relation to the distance vector respectively.

The scroll expander torque produced at a specified rotational speed mainly depends on the displaced expander volume per revolution of the orbiting scroll. However, the variable and constant wall thickness scroll expanders have different expander displacements due to different scroll geometrical parameters such as built-in volume ratio, suction chamber volume and others. For a fair performance comparison of the two scroll expanders, the torque can be averaged over one revolution of the orbiting scroll and divided by the corresponding averaged mass flow rate as shown in Eq. (4)

$$
\text { Torque per mass flow rate }=\frac{|\vec{\tau}|}{\overline{\bar{m}}}
$$

This enables an evaluation based on the brake mean effective pressure (BMEP) [36]. It is possible to compare the scroll expander performances at different pressure ratios in terms of their torque and regardless of their displacement. 


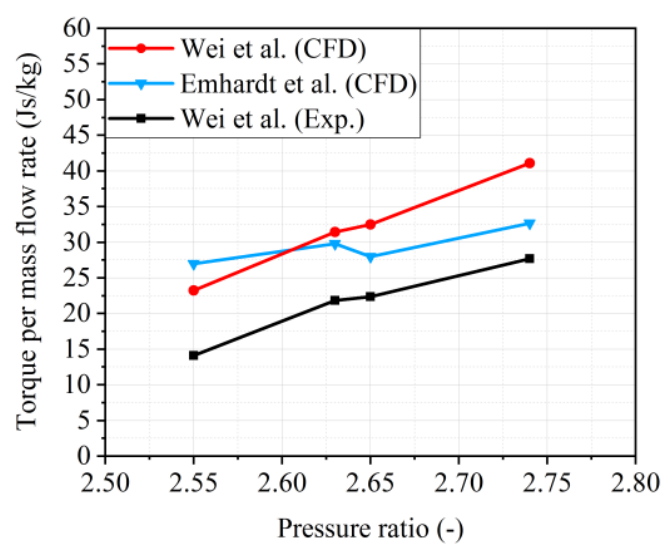

Fig. 4: Torque per mass flow rate for different pressure ratios

Fig. 4 illustrates the comparison of average torque per average mass flow rate for different pressure ratios with Wei et al.'s experimental and CFD results. The black and red curves in Fig. 4 represent the experimental and CFD results from Wei et al. (2015) [26] respectively. The blue curve shows the CFD results for the variable wall thickness design. It can be observed that the predicted average torques per average mass flow rates are in the range of the constant wall thickness CFD and experimental results. The variable wall thickness results lie between the CFD and experimental results of Wei et al. (2015) [26] except for the expander operation at a pressure ratio of 2.55. The different shapes of the curves are due to the different shapes of the geometries (constant vs. variable) and scroll tips (perfect meshing profile vs. dual arc tip design). More importantly, the two scroll expanders are examined at different operating conditions due to their different built-in volume ratio. The variable wall thickness design results are at a pressure ratio lower than the built-in volume ratio, whereas the constant wall thickness design was operated close to its optimum performance point. Overall, the comparison shows that the predictions for the CFD model are consistent with previous work.

In conclusion, it can be stated that the CFD model for the variable wall thickness scroll expander was successfully verified and validated. Minimal deviations resulted from grid and turbulence model sensitivity tests proving the CFD model assumptions. The predicted CFD results for the tangential force distributions and the 
comparison of average torque per average mass flow rate at different pressure ratios were consistent with existing data.

\section{Influence of increasing pressure ratio on the scroll expander performance}

The CFD results for variable wall thickness scroll expanders are analysed in this section. Isentropic efficiency and power output for increasing pressure ratio are examined first, followed by a second-law analysis to assess the expander performance concerning the exergy utilisation. The influence of variable wall thicknesses on the scroll expander aerodynamic performance, in particular, on the total pressure field and pressure-volume diagram, in addition to the unsteady and three-dimensional flow field is investigated.

\subsection{Isentropic efficiency and power output evaluation}

The predicted performance of scroll expanders can be compared with the performance based on ideal conditions by means of the isentropic efficiency. For both processes, the total pressure and total temperature at the scroll expander inlet in combination with the exit static pressure can be utilised to calculate the isentropic efficiency. The energy balance applied to a control volume of a scroll expander domain reads as follows

$$
\dot{Q}-\dot{W}=\dot{m}\left[\left(h_{t, \text { out }}-h_{t, \text { in }}\right)+g\left(z_{\text {out }}-z_{\text {in }}\right)\right]+\frac{d E_{\text {System }}}{d t}
$$

in which $\dot{W}$ represents the power output and $\dot{Q}$ the heat transfer of the system. $\dot{m}$ is specified as the mass flow rate through the system and $h_{t, o u t}$ and $h_{t, \text { in }}$ are denoted as the specific total enthalpies. Moreover, $g\left(z_{\text {out }}-z_{\text {in }}\right)$

defines the potential energy changes and $\frac{d\left(E_{S y s t e m}\right)}{d t}$ represents the change rate of the total energy contained inside the system. The actual and ideal processes were both assumed to be adiabatic. A further assumption is the neglect of potential energy changes. The isentropic efficiency $\left(\eta_{i s}\right)$ is subsequently defined as the actual power output $\left(\dot{W}_{h}\right)$ over the isentropic power output $\left(\dot{W}_{i s}\right)$ and can be expressed as

$$
\eta_{\text {is }}=\frac{\dot{W}_{h}}{\dot{W}_{\text {is }}}=\frac{\int_{t 1}^{t 2}\left(\dot{m}_{\text {in }} \cdot h_{t, \text { in }}\right) d t-\int_{t 1}^{t 2}\left(\dot{m}_{\text {out }} \cdot h_{t, \text { out }}\right) d t}{\int_{t 1}^{t 2}\left(\dot{m}_{\text {in }} \cdot h_{t, \text { in }}\right) d t-\int_{t 1}^{t 2}\left(\dot{m}_{\text {out }} \cdot h_{t, \text { out }, \text { is }}\right) d t}
$$


It is important to obtain the isentropic efficiency based on the specific total enthalpies at the scroll expander domain inlet and outlet $\left(h_{t, \text { in }}\right.$ and $\left.h_{t, o u t}\right)$ by considering the effects of the instantaneous mass flow rate at the scroll expander domain outlet $\left(\dot{m}_{\text {out }}\right)$ as shown in Eq. (6). The mass flow rate at the scroll expander domain inlet is defined as $\dot{m}_{i n}$. The specific total enthalpy of the isentropic process at the scroll expander domain outlet $\left(h_{t, o u t, i s}\right)$ can be determined with the help of the specific entropy at the inlet of the scroll expander domain $\left(s_{i n}\right)$ and the static pressure defined at the outlet of the domain $\left(p_{s, o u t}\right) \cdot t_{1}$ and $t_{2}$ specify the initial and final state of one revolution of the orbiting scroll.

To find the optimum performance point of the scroll expander, the isentropic efficiency and power output were calculated for increasing pressure ratio in the range from 2.5 up to 5.5 as listed in Table 7 . The pressure ratio was increased by increasing the inlet pressure whereas the static outlet pressure of $0.33 \mathrm{MPa}$ was kept constant. The investigations were performed for radial clearances of $200 \mu \mathrm{m}$ and $75 \mu \mathrm{m}$.

Table 7: Operating conditions for the CFD model with radial clearance of $75 \mu \mathrm{m}$

\begin{tabular}{llllll}
\hline $\begin{array}{l}\text { Pressure } \\
\text { ratio (-) }\end{array}$ & $\begin{array}{l}\text { Total inlet } \\
\text { pressure (MPa) }\end{array}$ & $\begin{array}{l}\boldsymbol{\eta}_{\text {is }} \\
(\mathbf{\%})\end{array}$ & $\begin{array}{l}\dot{\mathbf{m}} \\
(\mathbf{k g} / \mathbf{s})\end{array}$ & $\begin{array}{l}\dot{\mathbf{W}}_{\mathbf{a}} \\
(\mathbf{W})\end{array}$ & $\begin{array}{l}\dot{\mathbf{W}}_{\mathbf{a}} / \dot{\mathbf{W}}_{\mathbf{h}} \\
(-)\end{array}$ \\
\hline 2.50 & 0.825 & 53.44 & 0.018 & 177.17 & 1.00 \\
3.50 & 1.155 & 53.92 & 0.026 & 343.51 & 1.00 \\
4.00 & 1.320 & 53.00 & 0.030 & 427.71 & 1.01 \\
4.50 & 1.485 & 52.50 & 0.035 & 511.98 & 1.00 \\
5.00 & 1.650 & 51.49 & 0.040 & 596.77 & 0.99 \\
5.50 & 1.815 & 50.47 & 0.045 & 682.67 & 0.99 \\
\hline
\end{tabular}
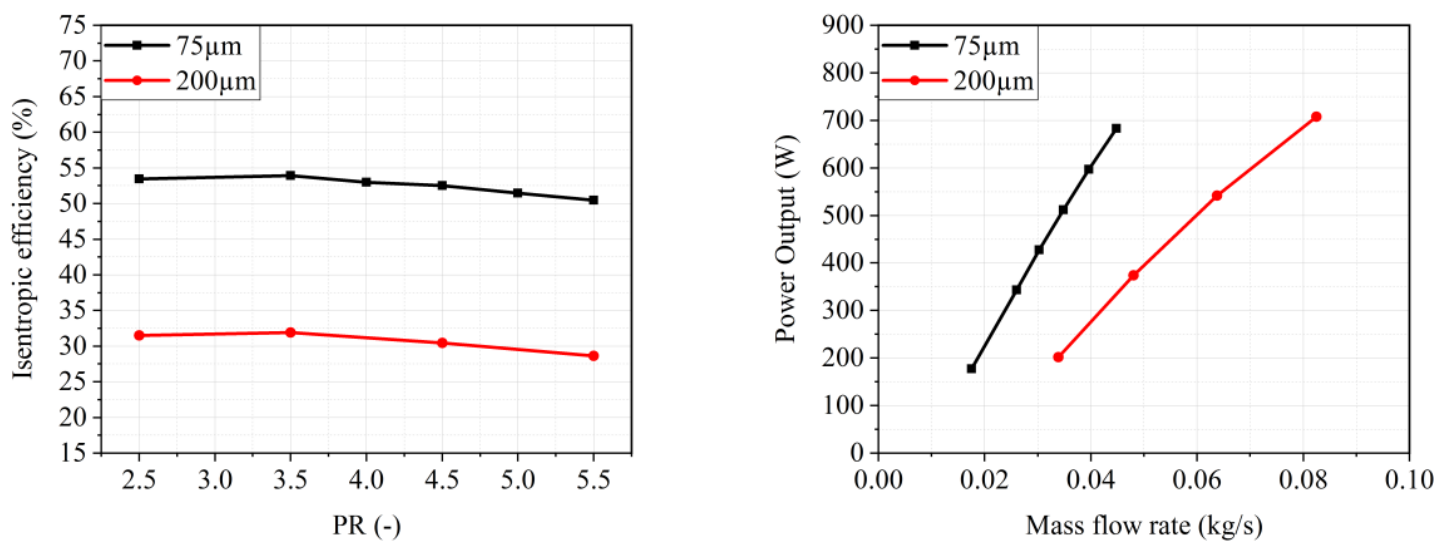

Fig. 5: Isentropic efficiency graphs for increasing pressure ratio (left) and power output for different mass flow rates (right) 
Fig. 5 illustrates the isentropic efficiency variation with pressure ratio (left) and power output variation with mass flow rate (right) for radial clearances of $200 \mu \mathrm{m}$ and $75 \mu \mathrm{m}$. Fig. 5 (left) shows that the isentropic efficiency increased for increasing pressure ratio until the optimum performance point was reached at a pressure ratio of 3.5 in each case. It is well known that the operation of scroll expanders in the over-expansion mode is more detrimental to performance than that in the under-expansion mode [10,37]. In the current case, however, the isentropic efficiencies predicted for the pressure ratios in the range of 4 to 5.5 are lower than those in the range of 2.5 to 3.5 . These trends are attributable to the assumptions being made. Specifically, actual and ideal processes were assumed to be adiabatic and mechanical friction losses were excluded. Furthermore, radial leakage through the axial clearances was neglected in the CFD model assumptions. In addition to the imbalance of pressure and built-in volume ratio, the flank leakage through the radial clearance was a factor contributing to the internal thermodynamic losses during the scroll expander working process. The conversion of kinetic energy into enthalpy due to fluid friction resulted in energy dissipation also contributing to the internal flow losses. Furthermore, the investigations of the impact of radial clearance on the expander performance reveal a much higher isentropic efficiency for the lower radial clearance of $75 \mu \mathrm{m}$. The isentropic efficiency values differ by almost $22 \%$ for the two clearances in each case $(\mathrm{PR}=2.5: 21.92 \% ; \mathrm{PR}=3.5: 21.98 \% ; \mathrm{PR}=4.5: 22.03 \%$ and $\mathrm{PR}=5.5: 21.85 \%)$.

Fig. 5 (right) depicts how increasing mass flow rates generated higher power outputs in both cases. The power output for the radial clearance of $75 \mu \mathrm{m}$ increased from $177.17 \mathrm{~W}$ to $682.67 \mathrm{~W}$ whereas the power output for the radial clearance of $200 \mu \mathrm{m}$ increased from $201.85 \mathrm{~W}$ to $707.99 \mathrm{~W}$ for the two pressure ratios of 2.5 and 5.5 in each case. This will be discussed further in the next section. It can be also noted that the mass flow rates were almost halved due to less internal flank leakage for smaller radial clearance. In other words, higher radial clearance led to higher mass flow rates which generated higher gas forces in spite of lower isentropic efficiency. 


\subsection{Second-law analysis}

Second-law analysis for scroll expanders can be carried out to qualitatively and quantitatively assess the scroll expander performance with regard to the exergy utilisation. Exergy is defined as the maximum amount of energy provided by a system at a specified environmental condition (dead state: $T_{0}=298.15 \mathrm{~K}$ and $\left.p_{0}=0.1 \mathrm{MPa}\right)$. Hence, the ratio between the exergy recovered by the scroll expander system and the exergy supplied to the scroll expander system along with the destroyed exergy can be examined. The exergy $\left(\psi_{i}\right)$ contained in fluid flow at a specified state $i$ can be expressed as

$$
\psi_{i}=\left(h_{t, i}-h_{t, 0}\right)-T_{0}\left(s_{i}-s_{0}\right)+g z_{i}
$$

where $h_{t, i}$ and $h_{t, 0}$ define the specific total enthalpies at the specified state (i) and at the dead state $(0)$ respectively. The specific entropies at the specified state (i) and the dead state (0) are represented by $s_{i}$ and $s_{o} . T_{0}$ is set as the dead state temperature and $g z_{i}$ as the potential energy at the state $i$ accordingly. Considering the change from the initial state (1) to the final state (2) as soon as the scroll expander working process has taken place, the exergy change $(\Delta \psi)$ of fluid flow during a scroll expander working process is defined as follows

$$
\Delta \psi=\psi_{1}-\psi_{2}=\left(h_{t, 1}-h_{t, 2}\right)-T_{0}\left(s_{1}-s_{2}\right)+g\left(z_{1}-z_{2}\right)
$$

The second-law efficiency of the scroll expander can be subsequently defined as the ratio between the actual power output $\left(\dot{W}_{h}\right)$ and the reversible power output $\left(\dot{W}_{\text {rev,out }}\right)$. The former is equal to the exergy recovered by the scroll expander system and the latter is defined as the greatest possible power output of the scroll expander system.

$$
\eta_{I I}=\frac{\dot{W}_{h}}{\dot{W}_{\text {rev }, \text { out }}}=\frac{\int_{t 1}^{t 2}\left(\dot{m}_{1} \cdot h_{t, 1}\right) d t-\int_{t 1}^{t 2}\left(\dot{m}_{2} \cdot h_{t, 2}\right) d t}{\int_{t 1}^{t 2}\left(\dot{m}_{1} \cdot \psi_{1}\right) d t-\int_{t 1}^{t 2}\left(\dot{m}_{2} \cdot \psi_{2}\right) d t}
$$


The mass flow rates at the initial state and the final state are specified as $\dot{m}_{1}$ and $\dot{m}_{2}$ in (Eq.) 9 .

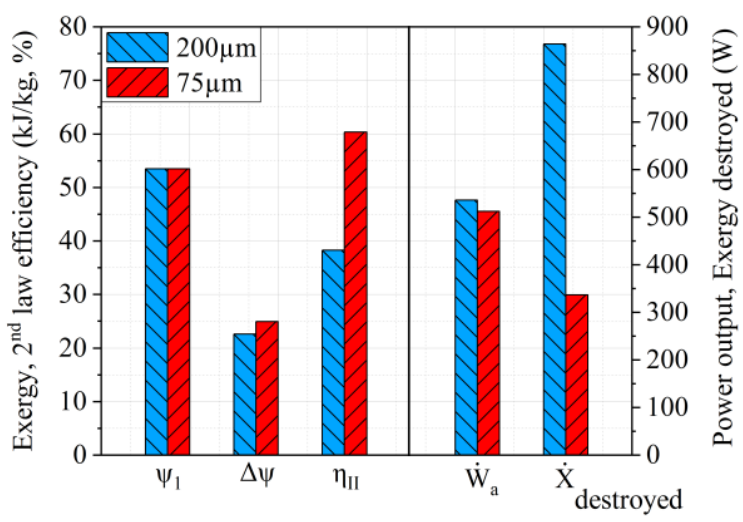

Fig. 6: Second-law analysis for different radial clearance at $P R=4.5$

The bar chart in Fig. 6 contains the results for the second-law analysis for different radial clearance at the same pressure ratio of 4.5 in each case. The exergy at the scroll expander inlets was identical in both cases since the applied boundary conditions were the same. The potential energies were neglected. The exergy changed by $24.92 \mathrm{~kJ} / \mathrm{kg}$ for the scroll expander with radial clearance of $75 \mu \mathrm{m}$ and by $22.63 \mathrm{~kJ} / \mathrm{kg}$ for the scroll expander with radial clearance of $200 \mu \mathrm{m}$ as shown in Fig. 6. Consequently, the scroll expander with the larger radial clearance produced a higher power output of $535.96 \mathrm{~W}$ in contrast to $512.33 \mathrm{~W}$ from the $75 \mu \mathrm{m}$ clearance expander. The destroyed exergy was $336.46 \mathrm{~W}$ for the scroll expander with radial clearance of $75 \mu \mathrm{m}$ and $864.23 \mathrm{~W}$ for the scroll expander with radial clearance of $200 \mu \mathrm{m}$. The evaluation of the second-law efficiency of the two scroll expanders reveals that $39.64 \%(75 \mu \mathrm{m})$ and $61.72 \%(200 \mu \mathrm{m})$ of the work potentials were destroyed during the scroll expander working process respectively due to the irreversibility in association with the internal leakages. Or in other words, $60.36 \%$ and $38.28 \%$ of the available work was converted by the two scroll expanders in each case. As a result, it can be concluded that the decrease of the radial clearance from $200 \mu \mathrm{m}$ to $75 \mu \mathrm{m}$ decreased the actual power output of the scroll expander by $4.41 \%$ but with the advantage of a much higher second-law efficiency. Much less exergy was destroyed during the scroll expander working process. 
Fig. 7 and 8 present total pressure distributions in the working chambers over one revolution of the orbiting scroll in the mid-axial xy-plane (at $\mathrm{z}=10 \mathrm{~mm}$ ). The working chambers comprise the suction, expansion and discharge chambers. The revolution of the orbiting scroll is subdivided into four steps with orbiting angles of $0^{\circ}$, $144^{\circ}, 240^{\circ}$, and $300^{\circ}$. The scroll expander with radial clearance of $75 \mu \mathrm{m}$ is used for the evaluation at the pressure ratio of 4.5 and the rotational speed of $n=2000 \mathrm{rpm}$. Fig. $7 \mathrm{a}$ depicts the beginning of the suction process at an orbiting angle of $0^{\circ}$. The suction chamber volume was approximately $0 \mathrm{~cm}^{3}$ and four expansion chambers (E1-E4) and two discharge chambers (D1 and D2) were formed. The scroll tip of the orbiting scroll separated expansion chambers E1 and E2. However, expansion chamber E1 was still connected with the suction port which enabled the aspiration of the working fluid into expansion chamber E1 in contrast to expansion chamber E2. Uneven pressure distributions were consequently generated in the expansion chambers, with the pressure in expansion chamber E1 higher than that in expansion chamber E2. A reduction from four to two expansion chambers can be noticed when the orbiting scroll rotated by $144^{\circ}$ as shown in Fig. $7 \mathrm{~b}$. The figure also reveals the beginning of the discharge process. The pressure in the discharge chambers was still higher than that in the outlet chambers. It can also be observed that the suction port is almost fully closed. The pressure imbalance was maintained in the two expansion chambers formed by the variable wall thicknesses with lower pressure in expansion chamber E2. According to the pressure distributions in Fig. 8a, the discharge chambers were fully opened and the pressure was equal to the pressure in the outlet chambers. In addition, the pressure in the expansion chambers further decreased along with increasing expansion chamber volumes as soon as the orbiting scroll rotated further as illustrated in Fig. 8a,b. The pressure gradients between the suction and expansion chambers drove the flow through the radial clearance in terms of flank leakages. It can be also seen how the discharge chambers were fully connected and coupled with the outlet chambers. The suction chamber almost reached its highest volume as demonstrated in Fig. $8 b$. 
To sum up, the geometrical effects of variable wall thicknesses did not affect the characteristic scroll machine operation. More specifically, the predicted total pressure distributions were similar to those obtained from CFD simulations for state of the art scroll expander geometries using constant wall thicknesses $[12,26,27]$. There was a blocking effect of the orbiting scroll tip which generated the characteristic pressure imbalances in the working chambers of the variable wall thickness scroll expander during the expansion process of the refrigerant vapour.

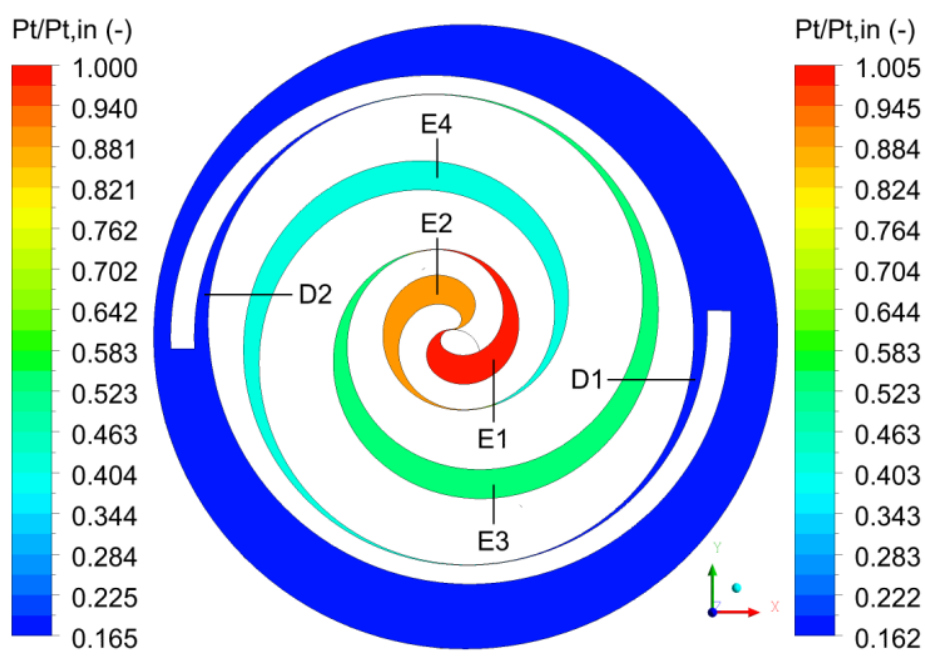

(a) Orbiting angle of $0^{\circ}$

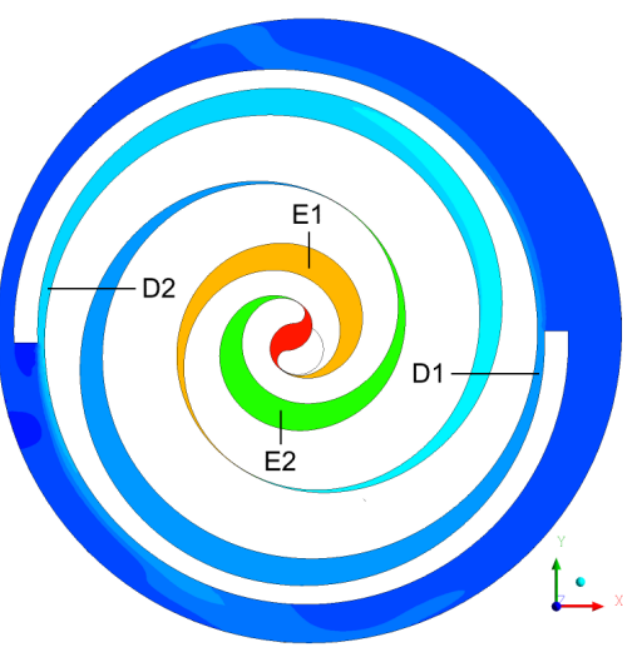

(b) Orbiting angle of $144^{\circ}$

Fig. 7: Total pressure fields in the mid-axial xy-plane (at $z=10 \mathrm{~mm}$ ) at two different orbiting angles of $0^{\circ}$ (a) and $144^{\circ}$ (b)

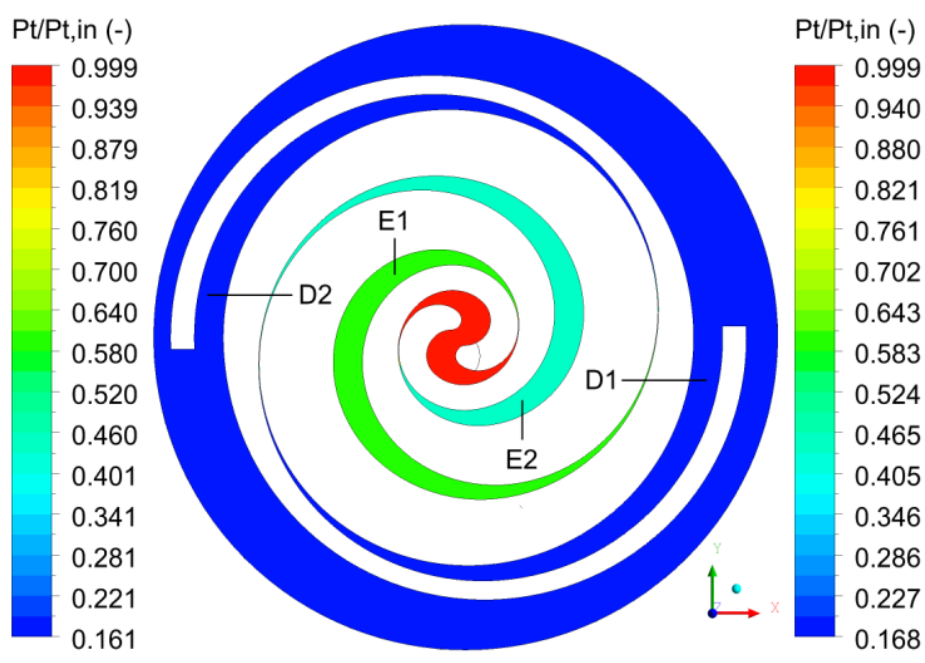

(a) Orbiting angle of $240^{\circ}$

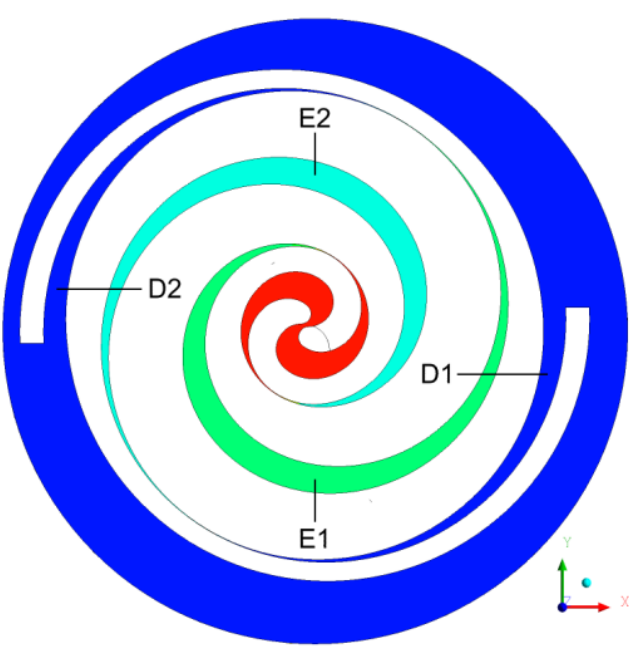

(b) Orbiting angle of $300^{\circ}$

Fig. 8: Total pressure fields in the mid-axial xy-plane (at $z=10 \mathrm{~mm}$ ) at two different orbiting angles of $240^{\circ}$ and $300^{\circ}$ 
Fig. 9 gives the pressure-crank angle diagram of a variable wall thickness scroll expander with radial clearance of $75 \mu \mathrm{m}$ at pressure ratios of $2.5,3.5,4.5$ and 5.5. The solid lines are the total pressure curves whereas the short dotted lines are the associated static pressure curves for each pressure ratio. Pressures for crank angles (CA) between $0^{\circ}$ and $359^{\circ}$ correspond to static and total pressures in the suction chamber whereas static and total pressures for crank angles between $360^{\circ}$ and $816^{\circ}$ correspond to those in the expansion chambers.

The crank angle of $0^{\circ}$ represents the start of the suction process when the suction chamber volume is approximately $0 \mathrm{~cm}^{3}$. At this point, the scroll tip of the orbiting scroll covered the suction port and interrupted the aspiration of the working fluid into the suction chamber. Consequently, there was a deviation between static and total pressure for each pressure ratio as shown in Fig. 9. This becomes more significant for increasing pressure ratio. In other words, the most kinetic energy generated during the suction process was at the pressure ratio of 5.5.

Total pressure fluctuations were observed at each pressure ratio similar to the corresponding static pressure oscillations. However, the total pressures in the suction chamber also increased with crank angles in each case until the total pressures reached the defined inlet pressures of $0.825 \mathrm{MPa}, 1.155 \mathrm{MPa}, 1.485 \mathrm{MPa}$ and $1.815 \mathrm{MPa}$ at crank angles of $132^{\circ}, 144^{\circ}, 168^{\circ}$ and $192^{\circ}$ respectively. The total pressure in the suction chamber started to decrease at a crank angle of $324^{\circ}$ for each pressure ratio. The highest suction chamber volume was reached at a crank angle of $359^{\circ}$. Or in other words, the suction process was finished as soon as one revolution of the orbiting scroll was completed. It can be noted that the unsteadiness of the suction process in a constant wall thickness scroll expander, including its transient flow characteristics, was described in detail in the study of Wei et al. (2015) [26].

The working fluid subsequently flowed into the two expansion chambers and the expansion process was started at the crank angles of $360^{\circ}$ in each case as presented in Fig. 9. It can be noted that the static and total pressures were almost equal for each pressure ratio throughout the entire expansion process. The total pressures of $0.379 \mathrm{MPa}(\mathrm{PR}=2.5), 0.521 \mathrm{MPa}(\mathrm{PR}=3.5), 0.672 \mathrm{MPa}(\mathrm{PR}=4.5)$ and $0.833 \mathrm{MPa}(\mathrm{PR}=5.5)$ were observed at the end of the expansion process at a crank angle of $816^{\circ}$. In all four cases, the fluid was under-expanded and therefore 
above the defined static outlet pressure of $0.33 \mathrm{MPa}$. The discharge chamber was formed and the discharge process began immediately afterwards.

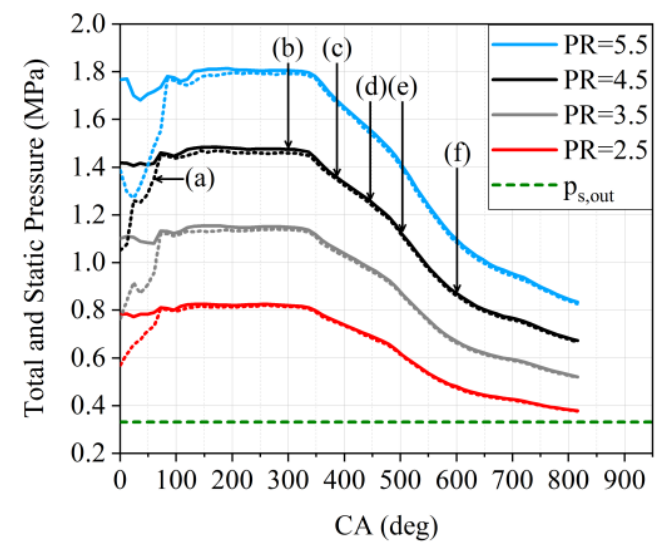

Fig. 9: Pressure-crank angle diagram for four different pressure ratios

It can be noted that Fig. 9 contains six coordinates ((a)-(f)) located on the pressure trace curves at six different crank angles of $60^{\circ}, 300^{\circ}, 384^{\circ}, 444^{\circ}, 504^{\circ}, 600^{\circ}$ for the pressure ratio of 4.5 . Following these crank angles, the transient and three-dimensional flow field in the suction and expansion chambers is visualised in Fig. 10. The streamlines in Fig. 10 represent the trajectories of the three-dimensional flow field. By analysing the streamlines, it can be seen that the working fluid streamed into the suction chamber at high speeds reaching a peak velocity of $30 \mathrm{~m} / \mathrm{s}$. This caused the deviation between static and total pressure as described previously. Fig. 10b reveals a decreasing flow velocity as the scroll rotated further $\left(\mathrm{CA}=300^{\circ}\right)$ reducing the pressure loss due to the generation of kinetic energy. It can be also seen that two vortices were generated in the suction chamber of the variable wall thickness scroll expander towards the end of the suction process as a result of the varying cross-sectional area of the intersection of suction port outlet and suction chamber [26].

The inflow to expansion chamber E1 was redirected to flow further downstream after it reached the scroll chamber top wall of E1 at the beginning of the expansion process as shown in Fig. 10c. The backflow towards the scroll expander inlet occurred after the fluid reached the narrowing part between the fixed and orbiting scroll walls creating the rotating vortex in E1. The energy dissipation rate of the rotating vortices in E1 and E2 increased for the increasing volumetric expansion at $\mathrm{CA}=444^{\circ}$ as visualised in Fig. 10d. In addition, there was a reduced energy 
supply during the closure of the suction port. The disconnection of $\mathrm{E} 1$ with the suction port at $\mathrm{CA}=504^{\circ}$ prevented the kinetic and pressure energy supply to E1 damping the intensity of the vortex in E1 significantly. Nonetheless, the energy dissipation rate of both vortices in E1 and E2 is comparable as illustrated in Fig. 10e. The pressure gradient driving the expansion process between (e) and (f) increased compared to (d) and (e) as illustrated in Fig. 9. The complete dissipation of the two vortices was observed towards the later stage of the expansion process at $\mathrm{CA}=600^{\circ}$ as shown in Fig. 10f. It should be stated that the flow field in the suction chamber is excluded in Fig.

$10 \mathrm{e}, \mathrm{f}$.

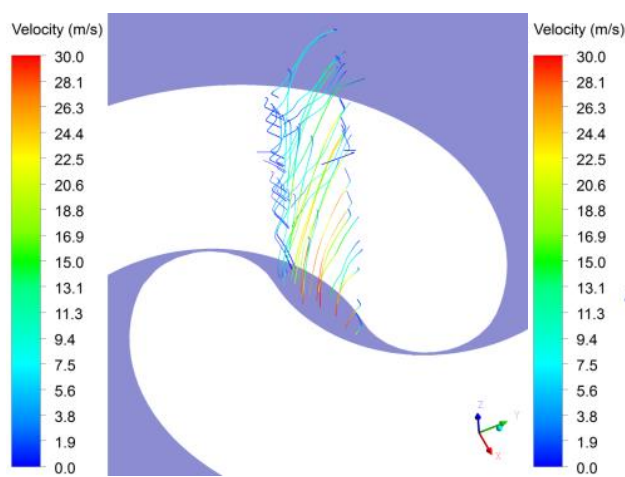

(a) $\mathrm{CA}=60^{\circ}$

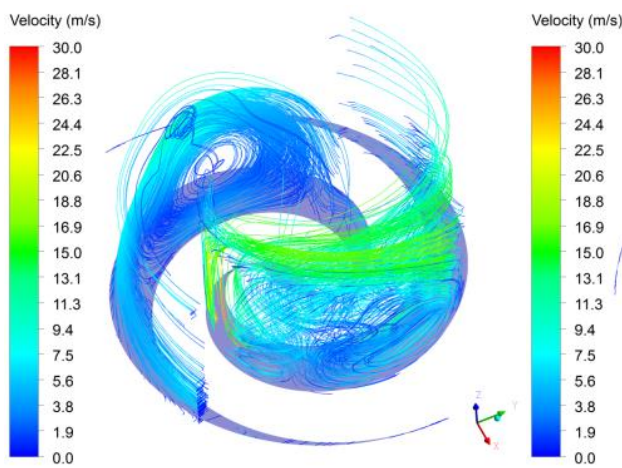

(d) $\mathrm{CA}=444^{\circ}$

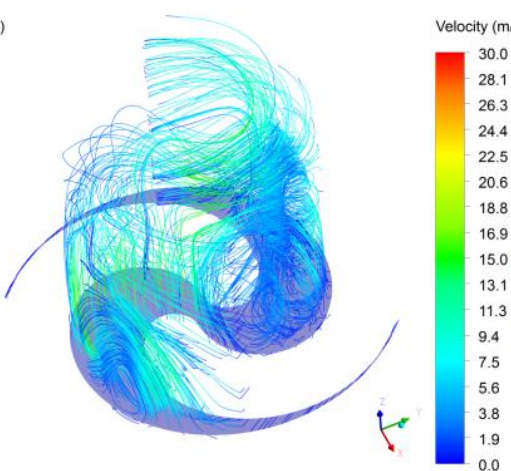

(b) $\mathrm{CA}=300^{\circ}$

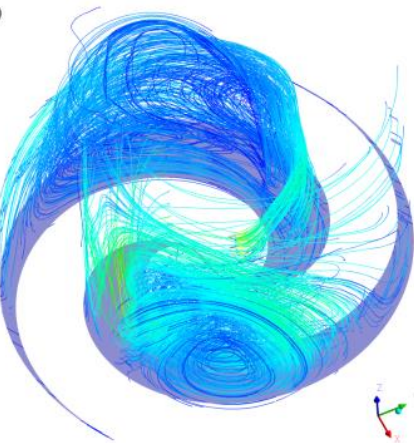

(c) $\mathrm{CA}=384^{\circ}$

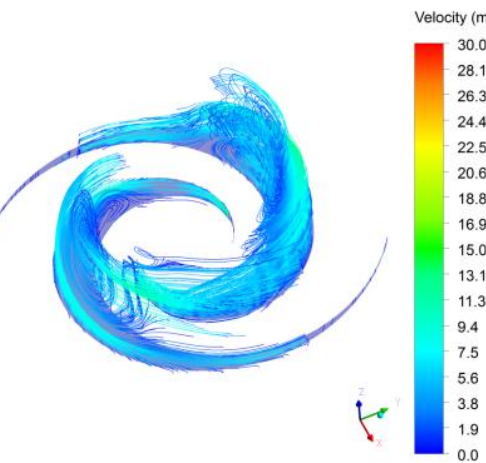

(e) $\mathrm{CA}=504^{\circ}$

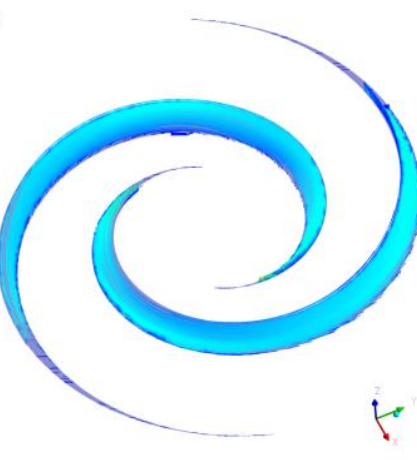

(f) $\mathrm{CA}=600^{\circ}$

Fig. 10: Generation of vortices during the suction process and their development during the expansion process

Fig. 11 depicts the $\mathrm{p}-\mathrm{V}$ diagram for the pressure ratio of 4.5 including the pressure traces in each individual expansion and discharge chamber. It should be indicated that expansion chambers E1 and E2 are specified in Fig. 7 and Fig. 8 in the previous section. Moreover, Fig. 11 contains six coordinates (I-VI) which are located on the pressure trace curves. It should be also indicated that these coordinates are different from those used in Fig. 9. For visualisation purposes and a better understanding of the expansion process, the transient total pressure 
distributions in the corresponding working chambers are marked in red in the mid-axial xy-plane (at $\mathrm{z}=10 \mathrm{~mm})$ at these coordinates as presented in Fig. 11.

The pressure traces further show the existing pressure imbalance in the two working chambers during the expansion process. The suction chamber was separated into two expansion chambers after the orbiting scroll finished one revolution. As a result, the total pressure in expansion chamber E1 (blue curve) had remained constant due to the existing connection to the suction port. The total pressure started to drop significantly as soon as the scroll tip of the orbiting scroll closed the suction port. In contrast, the total pressure in expansion chamber E2 (green curve) decreased as soon as the suction chamber was separated into two expansion chambers because it was disconnected from the suction port. The black curve defines the averaged total pressure in the two expansion chambers during the expansion of the working fluid. The total pressure further dropped to the defined static outlet pressure of $0.33 \mathrm{MPa}$ as soon as the discharge process was started. The discharge chamber volume decreased and the total pressure remained constant at $0.33 \mathrm{MPa}$ as the orbiting scroll rotated further.

The corresponding isentropic expansion is also included in Fig. 11. The isentropic expansion factor was assumed to be $\kappa=1.15$ based on the pressure and temperature range of the scroll expander working fluid [38]. The expansion process under isentropic conditions (orange curve) differed considerably from the expansion process predicted numerically. Note the over-expansion of the working fluid under isentropic conditions due to the geometrical effects of the variable wall thickness scroll design. It can be also noted that the total pressure at the end of the isentropic expansion process was below the defined static outlet pressure of $0.33 \mathrm{MPa}$. It was equal to $0.21 \mathrm{MPa}$ as soon as the maximum working chamber volume was achieved. In contrast to the total pressure at the end of the numerically predicted process which was under-expanded and therefore above the specified static outlet pressure as shown in Fig. 11. Leakage flows and irreversibility of the numerically predicted expansion process, including entropy generation inside the scroll expander working chambers, led to the deviation of the predicted and ideal $\mathrm{p}-\mathrm{V}$ curves. The entropy at the scroll expander outlet was larger for the numerically predicted process than that of the ideal process. The geometrical constraints of the expansion chambers formed by varying wall 
thicknesses restricted the expansion process. In theory, it should be feasible to achieve a complete expansion of the working fluid to the defined exit pressure by modifying the expansion chamber volume. The use of variable wall thickness scroll expanders with higher built-in volume ratios would lead to a higher expansion chamber volume at the end of the expansion process. The isentropic efficiency could thus be enhanced under the same operating conditions.

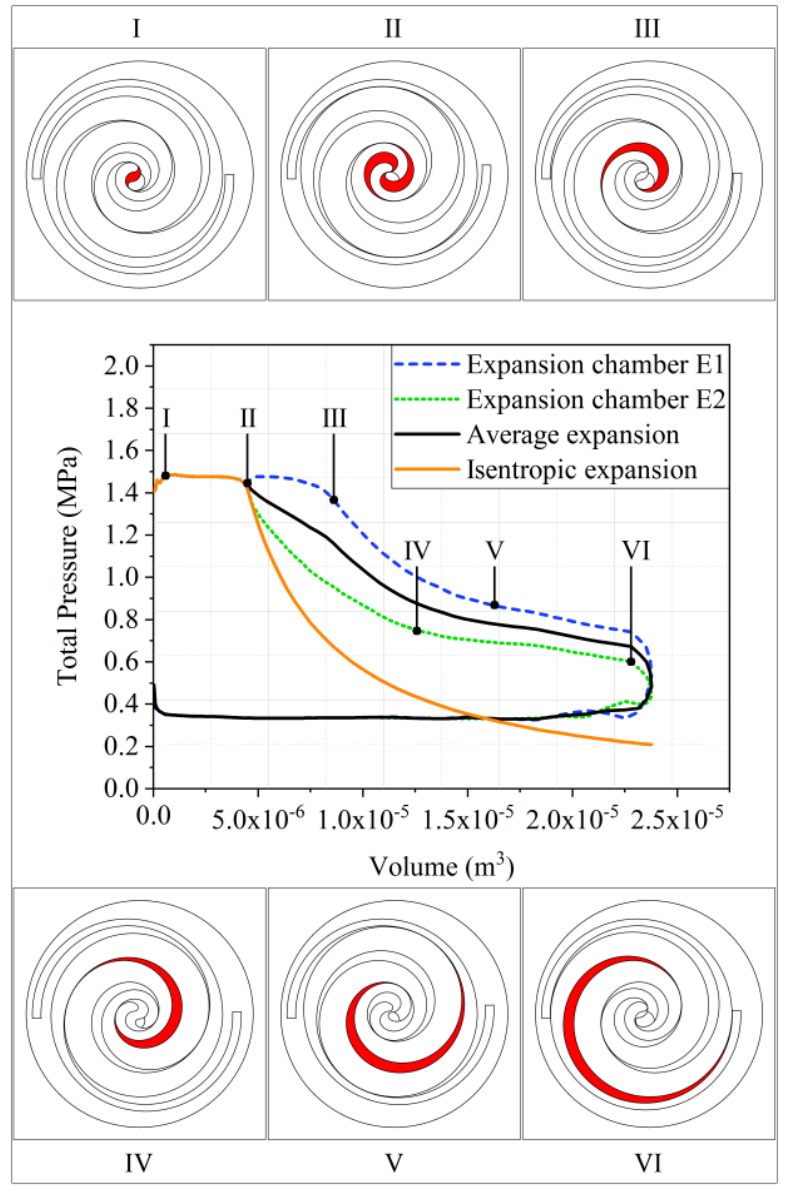

Fig. 11: $\mathrm{p}-\mathrm{V}$ diagram for the pressure ratio of 4.5

\section{Conclusions}

A CFD model for a scroll expander using variable wall thicknesses was developed. The model was characterised by a 3D domain and an unsteady approach and utilised the refrigerant R123 as the working fluid. The CFD model was verified and validated and the results were consistent with the predictions of the thermodynamic theory of scroll expanders. 
The optimum performance point was achieved at a pressure ratio of 3.5. The decrease of radial clearance from $200 \mu \mathrm{m}$ to $75 \mu \mathrm{m}$ had a positive effect on the isentropic efficiency and the specific power output. The isentropic efficiency at the optimum performance point was significantly improved by $22 \%$ from $31.9 \%$ to $53.9 \%$. The second-law analysis revealed that exergy of $336.5 \mathrm{~W}(75 \mu \mathrm{m})$ and $864.2 \mathrm{~W}(200 \mu \mathrm{m})$ were destroyed during the expansion processes and the second-law efficiencies were $60.4 \%$ and $38.3 \%$ respectively.

The geometrical effects of varying wall thicknesses did not affect the characteristic scroll machine operation. Pressure imbalances were observed in the expansion chambers of the variable wall thickness scroll expander design during the expander operation. The large-scale vortices, generated in the suction chamber during the suction process, were completely dissipated in the expansion chambers at a crank angle of $600^{\circ}$.

Geometrical constraints of the variable wall thickness geometry restricted the complete expansion of the working fluid. The use of scroll expanders with built-in volume ratios above 4.5 could fully expand the working fluid to its defined scroll expander outlet pressure. Compared to the variable wall thickness scroll expander used in this study, a higher isentropic efficiency could be achieved under the same operating conditions.

\section{Nomenclature}

\section{Roman Symbols}

$a$

$C_{o}, C_{1}, C_{2}, C_{3}$

$C_{\epsilon 1}, C_{\epsilon 2}, C_{\epsilon 3}$

$C_{\mu}$

$d$

$D_{S}$

$E_{\text {System }}$

$\overrightarrow{F_{n}}$

$\overrightarrow{F_{r}}$

$F_{t}$

$F_{x, i}, F_{y, i}$

$g$

$h$
Base circle radius (mm)

Constant of wall thickness (-)

Turbulence model coefficients (-)

Turbulence model coefficient (-)

Control parameter of wall thickness (-)

Non-dimensional specific diameter (-)

Total energy content $(\mathrm{J})$

Force vector in the normal direction $(\mathrm{N})$

Force vector in the radial direction $(\mathrm{N})$

Tangential force $(\mathrm{N})$

$\mathrm{x}$ and $\mathrm{y}$ components of the gas forces $(\mathrm{N})$

Gravitational acceleration $\left(\frac{m}{s^{2}}\right)$

Scroll height (mm) 


\begin{tabular}{|c|c|}
\hline$h_{t}$ & Specific total enthalpy $\left(\frac{\mathrm{J}}{\mathrm{kg}}\right)$ \\
\hline$k$ & Control parameter of wall thickness (-) \\
\hline$\dot{m}$ & Mass flow rate $\left(\frac{\mathrm{kg}}{\mathrm{s}}\right)$ \\
\hline$n$ & Rotational speed (rpm) \\
\hline$N_{s}$ & Non-dimensional specific speed (-) \\
\hline$p$ & Pressure (MPa) \\
\hline$p_{o}$ & Initial pressure $(\mathrm{MPa})$ \\
\hline$p_{s}$ & Static pressure $(\mathrm{MPa})$ \\
\hline$p_{t}$ & Total pressure $(\mathrm{MPa})$ \\
\hline$\dot{Q}$ & Heat transfer rate $(\mathrm{W})$ \\
\hline$R$ & Big circular arc radius (mm) \\
\hline$r$ & Small circular arc radius $(\mathrm{mm})$ \\
\hline$r_{v}$ & Built-in volume ratio (-) \\
\hline $\overrightarrow{r_{0}}$ & Distance vector $(\mathrm{m})$ \\
\hline$r_{o b}$ & Orbiting radius of the moving scroll (mm) \\
\hline$s$ & Specific entropy $\left(\frac{J}{k g K}\right)$ \\
\hline$S_{\phi}$ & Source term of the scalar \\
\hline$t$ & Time (s) \\
\hline$t_{1}$ and $t_{2}$ & Initial and final state of one revolution of the orbiting scroll \\
\hline$T$ & Time period (s) \\
\hline$T_{0}$ & Dead state temperature $(\mathrm{K})$ \\
\hline$\vec{u}$ & Flow velocity vector $\left(\frac{m}{s}\right)$ \\
\hline$\vec{u}_{g}$ & Mesh velocity of the moving mesh $\left(\frac{m}{s}\right)$ \\
\hline$V$ & Arbitrary control volume $\left(\mathrm{m}^{3}\right)$ \\
\hline$\dot{W}$ & Power output (W) \\
\hline$\dot{W}_{a}$ & Power output calculated from angular momentum change (W) \\
\hline$\dot{W}_{h}$ & Power output calculated from enthalpy change (W) \\
\hline$\dot{W}_{\text {rev,out }}$ & Power output under reversible conditions (W) \\
\hline$\dot{X}$ & Exergy destroyed (W) \\
\hline$z$ & Vertical position (m) \\
\hline
\end{tabular}

Greek Symbols

$\begin{array}{ll}\alpha & \text { Original angle (rad) } \\ \alpha_{i} & \text { Initial angle of the inner involute (rad) } \\ \alpha_{o} & \text { Initial angle of the outer involute (rad) } \\ \beta & \text { Turbulence model coefficient (-) } \\ \Gamma & \text { Diffusion coefficient (-) }\end{array}$


$\eta_{\text {is }}$

$\eta_{0}$

$\eta_{I I}$

$\rho$

$\sigma_{k}, \sigma_{\epsilon}$

$\tau$

$\phi$

$\psi$

Subscripts

$\begin{array}{ll}\text { ave } & \text { average } \\ \text { i } & \text { inner involute } \\ \text { in } & \text { scroll expander inlet } \\ \text { is } & \text { isentropic } \\ \text { o } & \text { outer involute } \\ \text { ob } & \text { orbiting } \\ \text { out } & \text { scroll expander outlet } \\ 1 & \text { initial state } \\ 2 & \text { final state }\end{array}$

Acronyms/Abbreviations

2D

Two-dimensional

3D

Three-dimensional

BMEP

$\mathrm{CA}$

CFD

D1, D2

E1 - E4

NIST

ORC

PISO

PMP

PR

Crank angle (deg)

Organic Rankine cycle

Perfect Meshing Profile

Pressure Ratio (-)
Physical time step (s)

Rate of dissipation of turbulence energy $\left(\frac{m^{2}}{s^{3}}\right)$

Isentropic efficiency (\%)

Turbulence model coefficient (-)

Second-law efficiency (\%)

Isentropic exponent for a real gas (-)

Turbulent kinetic energy $\left(\frac{m^{2}}{s^{2}}\right)$

Fluid density $\left(\frac{\mathrm{kg}}{\mathrm{m}^{3}}\right)$

Turbulence model coefficients (-)

Torque generated by gas forces $(\mathrm{Nm})$

General scalar (-)

Exergy $\left(\frac{\mathrm{kJ}}{\mathrm{kg}}\right)$

Angular velocity $\left(\frac{r a d}{s}\right)$

Brake Mean Effective Pressure (kPa)

Computational Fluid Dynamics

Discharge chambers D1 and D2 (-)

Expansion chamber E1 - E4 (-)

National Institute of Standards and Technology

Pressure-Implicit with Splitting of Operators 


$\begin{array}{ll}\text { PRESTO } & \text { PREssure STaggering Option } \\ \text { REFPROP } & \text { Reference Fluid Thermodynamic and Transport Properties Database } \\ \text { R123 } & \text { 2,2-Dichloro-1,1,1-trifluoroethane } \\ \text { R245fa } & \text { 1,1,1,3,3-Pentafluoropropane } \\ \text { RNG } & \text { Re-Normalisation Group } \\ \text { rpm } & \text { Revolutions per minute }(\mathrm{Hz}) \\ \text { URANS } & \text { Unsteady Reynolds-Averaged Navier-Stokes }\end{array}$

\section{References}

[1] G. Qiu, H. Liu, and S. Riffat. Expanders for micro-CHP systems with Organic Rankine Cycle, Applied Thermal Engineering. 31, pages 3301-3307, 2011

[2] J. Bao, L. Zhao. A review of working fluid and expander selections for Organic Rankine Cycle, Renew. Sustain. Energy Rev. 24, pages $325-342,2013$

[3] S. Quolilin, M. VanDenBroek, S. Declaye, P. Dewallef, and V. Lemort. Techno-economic survey of Organic Rankine Cycle (ORC) systems, Renew. Sustain. Energy Rev. 22, pages 168-186, 2013

[4] K. Rahbar, S. Mahmoud, R. K. Al-Dadah, N. Moazami, and S. A. Mirhadizadeh. Review of organic Rankine cycle for small-scale applications, Energy Conversion and Management 134, pages 135-155, 2017

[5] O. Dumont, A. Parthoens, R. Dickes and V. Lemort. Experimental investigation and optimal performance assessment of four volumetric expanders (scroll, screw, piston, and roots) tested in a small-scale organic Rankine cycle system. Energy 165, pages 1119-1127, 2018

[6] L. E. Olmedo, V. Mounier, L. C. Mendoza, and J. Schiffmann. Dimensionless correlations and performance maps of scroll expanders for micro-scale Organic Rankine Cycles. Energy 156, pages 520-533, 2018

[7] R. Zanelli and D. Favrat. Experimental investigation of a hermetic scroll expander-generator, in: Proc. Int. Compress. Eng. Conf., Purdue, Paper 1021, 1994.

[8] V. Lemort, S. Declaye, and S. Quoilin. Experimental characterization of a hermetic scroll expander for use in a micro-scale Rankine cycle, Proc. Inst. Mech. Eng. Part A: Journal of Power and Energy 226, 2012

[9] S. Declaye, S. Quoilin, L. Guillaume, V. Lemort. Experimental study on an open-drive scroll expander integrated into an ORC (Organic Rankine Cycle) system with R245fa as working fluid, Energy 55, pages 173-183, 2013

[10] V. Lemort, S. Quoilin, C. Cuevas, J. Lebrun. Testing and modeling a scroll expander integrated into an Organic Rankine Cycle, Applied Thermal Engineering 29, pages 3094-3102, 2009

[11] S. Clemente, D. Micheli, M. Reini and R. Taccani. Energy efficiency analysis of Organic Rankine Cycles with scroll expanders for cogenerative applications. Applied Energy 97, pages 792-801, 2012

[12] J.-C. Chang, C.-W. Chang, T.-C. Hung, J.-R. Lin and K.-C. Huang. Experimental study and CFD approach for scroll type expander used in low-temperature organic Rankine cycle. Applied Thermal Engineering 73, pages 1444-1452, 2014

[13] J.-C. Chang, T.-C. Hung, Y.-L. He, W. Zhang. Experimental study on low-temperature organic Rankine cycle utilizing scroll type expander, Applied Energy 155, pages 150-159, 2015

[14] S. Emhardt, G. Tian and J. Chew. A review of scroll expander geometries and their performance. Applied Thermal Engineering 141, pages $1020-1034,2018$

[15] J.W. Bush and W.P. Beagle. Derivation of a general relation governing the conjugacy of scroll profiles. in: Proc. International Compressor Engineering Conference, Purdue, Paper 902, 1992

[16] J.W. Bush, W.P. Beagle, and M.E. Housman. Maximizing scroll compressor displacement using generalized wrap geometry, in: Proc. Int. Compress. Eng. Conf., Purdue, Paper 981, 1994

[17] J. Gravesen, C. Henriksen, The geometry of the scroll compressor, Siam Rev. Vol. 43, No. 1, pages 113-126, 2001

[18] P. Bin, V. Lemort, A. Legros, Z. Hongsheng and G. Haifeng. Variable thickness scroll compressor performance analysis - part I: Geometric and thermodynamic modelling. in: Proc. IMechE. Part E: Journal of Process Mechanical Engineering Vol. 231, pages 633-640, 2016

[19] P. Bin, V. Lemort, A. Legros, Z. Hongsheng and G. Haifeng. Variable thickness scroll compressor performance analysis - part II: Dynamic modelling and model validation. in: Proc. IMechE. Part E: Journal of Process Mechanical Engineering Vol. 231, pages 641-649, 2016

[20] Y. Liu, C. Hung, and Y. Chang. Study on involute of circle with variable radii in a scroll compressor, Mech. Mach. Theory 45, pages $1520-1536,2010$

[21] Y. Liu, Y. Tang, Y. Chang and Y. Yang. Optimum design of scroll profiles created from involute of circle with variable radii by using finite element analysis, Mech. Mach. Theory 55, pages 1-17, 2012

[22] B.R. Shaffer and E.A. Groll. Variable wall thickness scroll geometry modeling with use of a control volume approach, International Journal of Refrigeration 36, pages 1809-1820, 2013

[23] K.T. Ooi and J. Zhu. Convective heat transfer in a scroll compressor chamber: a 2-D simulation. International Journal of Thermal Sciences 43, pages $677-688,2004$

[24] M. Morini, C. Pavan, M. Pinelli, E. Romito, and A. Suman. Analysis of a scroll machine for micro ORC applications by means of a RE/CFD methodology. Applied Thermal Engineering 80, pages 132-140, 2015

[25] P. Song, M. Wei, L. Shi, S.N. Danish, and C. Ma. A review of scroll expanders for organic Rankine cycle systems. Applied Thermal Engineering 75, pages 54-64, 2015

[26] M. Wei, P. Song, B. Zhao, L. Shi, Z. Wang and C. Ma. Unsteady flow in the suction process of a scroll expander for an ORC waste heat recovery system. Applied Thermal Engineering 78, pages 460-470, 2015

[27] P. Song, M. Wei, Z. Liu, B. Zhao. Effects of suction port arrangements on a scroll expander for a small scale ORC system based on CFD approach. Applied Energy 150, pages 274-285, 2015

[28] P. Song, M. Wei, Y. Zhang, L. Sun, S. Emhardt and W. Zhuge. The impact of a bilateral symmetric discharge structure on the performance of a scroll expander for ORC power generation system, Energy 158, pages 458-470, 2018

[29] J. Rak, S. Pietrowicz, and Z. Gnutek. The scroll compressor with internal cooling system in cryogenic applications. in: Proc. International Compressor Engineering Conference, Purdue, Paper 2365, 2014 
[30] J. Rak, S. Pietrowicz, and Z. Gnutek. The scroll compressor with internal cooling system - conception and CFD analysis. in: Proc. International Compressor Engineering Conference, Purdue, Paper 2364, 2014

[31] S. Emhardt, P. Song, G. Tian, J. Chew, and M. Wei. CFD analysis of variable wall thickness scroll expanders integrated into small scale ORC systems, Energy Procedia 158, pages 2272-2277, 2019

[32] Inc. ANSYS. Ansys Fluent theory guide release 15.0, 2013

[33] A. Suman, C. Buratto, N. Aldi, M. Pinelli, P.R. Spina, and M. Morini. A comparison between two different CFD approaches of a real scroll expander for micro-ORC applications. $3^{\text {rd }}$ International Seminar on ORC Power Systems, 2015.

[34] J. Wang, Y. Song, Q. Li, and D. Zhang. Novel structured dynamic mesh generation for CFD analysis of scroll compressors. Proc

IMechE Part A: J Power and Energy, Vol. 229, 2015

[35] NIST Reference Fluid Thermodynamic and Transport Properties Database (REFPROP): Version 9.1. https://www.nist.gov/srd/refprop (accessed 24/09/2019)

[36] J.B. Heywood. Internal Combustion Engine Fundamentals, 1988

[37] G. Xiaojun, L. Liansheng, Z. Yuanyang and S. Pengcheng. Research on a Scroll Expander Used for Recovering Work in a Fuel Cell. Int. J. of Thermodynamics, Vol.7, No.1, pages 1-8, 2004

[38] DuPont Suva Refrigerants. https://www.chemours.com/Refrigerants/en US/assets/downloads/h47753 hcfc123 thermo prop eng.pdf (accessed 03/06/2019) 